\title{
Free Radical Scavenging and Antioxidant Activity of Silver Nanoparticles Synthesized from Flower Extract of Rhododendron dauricum
}

Amit Kumar Mittal, Abhishek Kaler and Uttam Chand Banerjee*

Department of Pharmaceutical Technology (Biotechnology), National Institute of Pharmaceutical Education and Research, Sector-67, SAS Nagar 160062 Punjab, India

* Corresponding author: ucbanerjee@niper.ac.in

Tel: +91-172-2214682-87, Fax: +91-172-2214692

\begin{abstract}
A simple and efficient eco-friendly approach for the biosynthesis of stable, monodisperse silver nanoparticles (AgNPs) using Rhododendron dauricum flower extract is described. Different reaction parameters (concentration of plant extract, substrate concentration, $\mathrm{pH}$, temperature and reaction time) were optimized to synthesize AgNPs with controlled properties. AgNPs were characterized in terms of synthesis, size distribution (PDI of 0.25), capping functionalities (phenolic compounds) and microscopic evaluation by UV-Visible spectroscopy, dynamic light scattering, Fourier Transform Infrared (FTIR) spectroscopy and Transmission Electron Microscope (TEM). The specific characteristics and loss of organic content (1.81 mg) of the synthesized nanoparticles was measured by Differential Scanning Calorimetry (DSC) and Thermo Gravimetric Analysis (TGA). The results showed the simplistic and feasible approach for obtaining stable aqueous monodispersive AgNPs. Further, the antioxidant activity of AgNPs imparted by plant phenolic components was evaluated using DPPH assay and found to be comparable to standard TROLOX.
\end{abstract}

Keywords: Green synthesis, Silver nanoparticles, Plant extracts, Antioxidants assay

Citation: Amit Kumar Mittal, et al. Free Radical Scavenging and Antioxidant Activity of Silver Nanoparticles Synthesized from Flower Extract of Rhododendron dauricum . Nano Biomed. Eng. 2012, 4(3), 118-124. DOI: 10.5101/nbe.v4i3.p118-124.

\section{Introduction}

Silver nanoparticles (AgNPs) have a wide range of applications in various fields from electronics to biology, pharmaceuticals to medical diagnosis and therapeutics to biosensor development [1,2]. To maximize the use of nanosized metal nanoparticles (MNPs), a large spectrum of research has been focused to control the size and shape that reflects in their chemical and optical properties [3]. Various physical and chemical methods were extensively used to synthesize monodispersed AgNPs [4]. Silver NPs synthesized by the reduction of aqueous $\mathrm{Ag}^{+}$ions using plant extract has been reported in literature $[5,6]$. This green chemistry approach towards the synthesis of AgNPs has many advantages such as, less reaction time (few minutes) compared to hours taken by microbial counterpart $[7,8]$. Cost effectiveness, ease of scale up, economic viability and most importantly eco-friendly nature [9]. Certain reports highlighting role of plant constituents in formation and stabilization of AgNPs have been published [10-13].

In the present study, silver nanoparticles have been synthesized using flower extract of Rhododendron dauricum. Water was used as the environment benign reaction medium and plant metabolites as reducing and capping agent, making the process greener one. Interaction between metal nanoparticles and capping agents is not much documented and properties that nanoparticles may acquire as a result of these interactions are even less reported. Keeping in view the antioxidant constituents present in $R$. dauricum flower part and their possible interaction with metallic surface, we investigated the antioxidant potential of silver nanoparticles capped by 
these components.

\section{Materials and methods}

\subsection{Reagents}

Silver nitrate used for biosynthesis of AgNPs was purchased from Sigma-Aldrich (Steinheim, Germany). Fresh Rhododendron dauricum flowers were purchased from the flower market, Sector-26, Chandigarh, India. Incubator Shaker (Innova 4230) and UV-Vis Spectrophotometer (U-3010, HITACHI) were used to characterize AgNPs formation. DPPH (1,1-diphenyl-2-picrylhydrazyl) and TROLOX (2,2'-azino-bis (3-ethylbenzthiazoline-6sulphonic acid)) were purchased from Sigma-Aldrich, USA.

\subsection{Preparation of the flower extract}

Flower parts of Rhododendron dauricum were thoroughly washed and dried completely in the shade. Dried parts were cut into small pieces and powdered in a grinder. Fifty gram of powder was suspended in $500 \mathrm{~mL}$ deionized water and extracted at $50{ }^{\circ} \mathrm{C}$ for $120 \mathrm{~min}$. The extract was filtered and stored at $4{ }^{\circ} \mathrm{C}$ for NPs synthesis.

\subsection{Green synthesis and characterization of AgNPs}

The aqueous flower extract of $R$. dauricum was used in the bioreduction of silver ions. In a typical experiment, $\mathrm{AgNO} 3$ was added to aqueous solution of plant extract. The reaction was allowed to proceed at $35^{\circ} \mathrm{C}$ and 200 $\mathrm{rpm}$ in the dark environment. Two controls were used (one without flower extract i.e., only silver nitrate in deionised water and other without silver nitrate i.e. only plant extract in deionised water). The reaction mixture was periodically observed for the change in colour and analyzed by UV-Vis spectrophotometer in the range of $300-800 \mathrm{~nm}$. The size and potential of nanoparticles were estimated by Zeta-Sizer. Nanoparticles were harvested using centrifugation $(7000 \times \mathrm{g}, 15 \mathrm{~min})$ and washed thrice using deionised water to remove plant extract material. Pellet of nanoparticles was resuspended in deionised water and freeze dried using Lyophilizer. The functional groups capping of the synthesized NPs was confirmed by FTIR Spectroscopy. The size and shape of AgNPs was determined using High Resolution Transmission Electron Microscope. The stability and degradation of plant extract capped NPs was assessed using Differential Scanning Calorimetry and Thermo Gravimetric Analysis.

\subsection{Optimization of various parameters to increase the nanoparticles synthesis}

\subsubsection{Concentration of plant extract}

Ratio of metal ions to reducing agent affects the rate of synthesis as well as the size and shape of nanoparticles. To synthesize NPs from flower extract of $R$. dauricum different concentrations of extract were prepared from stock solution. Concentrated extracts ( 1 to $10 \mathrm{~mL}$ ) were diluted to $100 \mathrm{~mL}$ with deionised water to prepare reducing solution of different concentrations. Silver salt was added to these dilutions and reaction mixture was incubated at $35^{\circ} \mathrm{C}(200 \mathrm{rpm})$ in dark condition.

\subsubsection{Silver ion concentration}

To optimize the initial silver ion concentration, the flasks were incubated $\left(35^{\circ} \mathrm{C}, 200 \mathrm{rpm}\right)$ containing different concentrations of $\mathrm{AgNO}_{3}(0.5-5 \mathrm{mM})$ with fixed concentration of plant extracts ( 0.02 dilution) in dark condition.

\subsubsection{Temperature and $\mathrm{pH}$}

Reaction flasks containing plant extract (0.02 dilution) and $4 \mathrm{mM} \mathrm{AgNO}_{3}$ were incubated at temperatures ranging from $25-65{ }^{\circ} \mathrm{C}$ under shaking condition (200 rpm). Similarly reaction mixture having initial $\mathrm{pH}$ in the range of 3 to 13 was incubated at $35^{\circ} \mathrm{C}$ under shaking condition (200 rpm) keeping other parameters constant.

\subsubsection{Reaction time}

To optimize reaction time in terms of yield and properties of nanoparticles, samples were collected at various time intervals $(6,12,24,36,48$ and $72 \mathrm{~h}$.) from the reaction mixture and subjected to further characterization.

\subsection{Free radical (anti-oxidant) scavenging activity: DPPH assay}

Free radical (anti-oxidant) scavenging activity of the AgNPs was determined by the DPPH assay [14]. Ethanolic solution of DPPH was prepared to a final concentration of $200 \mu \mathrm{M}$ and served as negative control. Similarly different concentrations of AgNPs (25-100 $\left.\mu \mathrm{g} \mathrm{mL}{ }^{-1}\right)$ in water were prepared. Reaction mixture was prepared by adding $100 \mu \mathrm{L}$ silver nanoparticle having a range of concentration into $100 \mu \mathrm{L}$ DPPH solution. The reaction mixture was incubated for half an hour at room temperature under shaking condition and the absorbance was measured at $517 \mathrm{~nm}$ in 96 well plate. The change in absorbance with respect to the control (containing DPPH only) is calculated as percentage scavenging activity. TROLOX solution was used as positive control. The assay was performed in duplicate.

\section{Results and discussion}

\subsection{Visual inspection and UV-Vis spectroscopy analysis}

Due to Surface Plasmon Resonance, AgNPs show yellowish brown to dark brown colour, depending upon their size and shape [15]. Preliminary identification of nanoparticle formation was carried out by observing the colour change of the reaction solution. Colloidal solution of AgNPs was subjected to UV-Vis spectral analysis where sharp bands of silver colloids were observed at $400-450 \mathrm{~nm}$ (Fig. 1a) as previously reported by other workers $[5,16]$. Two control reactions were kept as shown in Fig. $1 \mathrm{~b}$ i.e. aqueous solution of $\mathrm{AgNO}_{3}$ which is without any colour and plant extract solution that exhibit pale yellow colour. Reaction mixture containing $\mathrm{AgNO}_{3}$ 


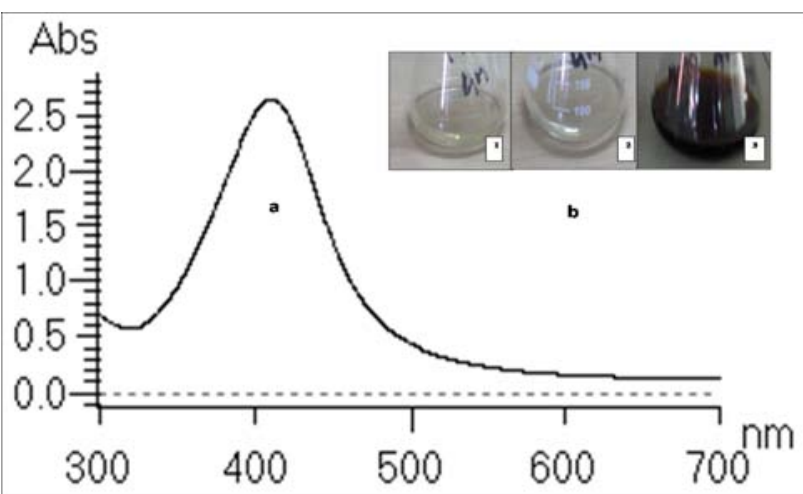

Fig. 1 UV-Vis spectrum of (a) AgNPs produced by reaction of plant extract with silver nitrate $(1 \mathrm{mM})$ in 24 h. (b) aqueous solution ofAgNO3 (control 1), plant extract solution without silver nitrate (control 2) and reaction mixture (3) incubated at $35^{\circ} \mathrm{C}, 200 \mathrm{rpm}$

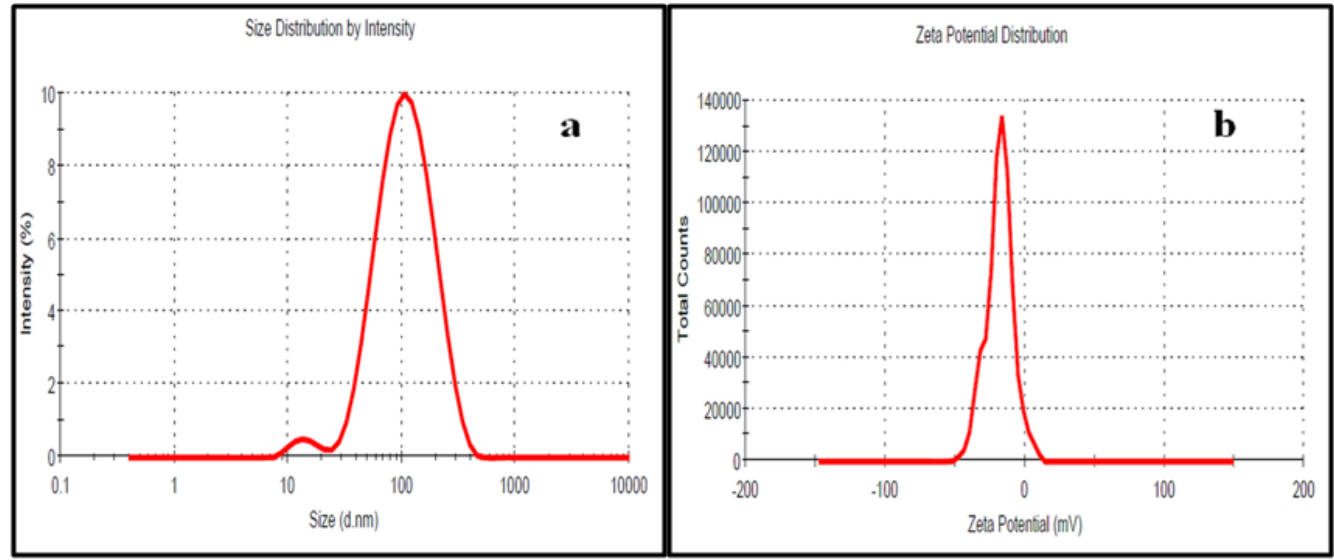

Fig. 2 (a) Particle size distribution and (b) zeta potential of silver nanoparticles synthesized by flower extract of Rhododendron dauricum

and plant extract shows brown colouration indicating formation of AgNPs in the reaction mixture. Parallel control experiments didn't show any absorption at 420 nm.

The stability of the AgNPs was studied for a period of three month. UV-Vis spectral analysis of lyophilized silver nanoparticles was carried out to check its stability after dispersion in water. The results showed similar monodispersity and chemical stability of the nanoparticles which are well dispersed in solution without any aggregation.

\subsection{Zeta sizer}

The average hydrodynamic size (Fig. 2a) and zeta potential (Fig. 2b) of AgNPs in aqueous solution was found to be $89 \mathrm{~nm}$ and $-18 \mathrm{mV}$, respectively. PDI of 0.25 indicates good monodispersity and zeta potential indicates capping of NPs by negatively charged groups (Fig. 2b).

\subsection{TEM analysis}

A representative TEM image of the prepared AgNPs is shown in the Fig. 3. TEM image shows that the synthesized NPs lie in the size range of 25-40 nm and capped by plant constituents that prevented their aggregation. Silver nanoparticles of similar size were prepared by Cinnamomum camphora leaf extract [17]. Inherent capping offers additional advantage of the stability in the green chemical synthesis (Fig. 3) [18]. This stability attributes of the plant constituents are in

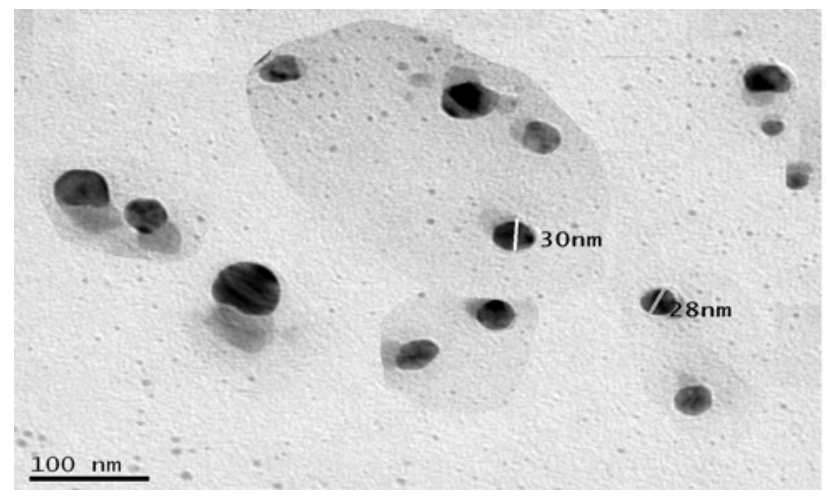

Fig. 3 TEM image of silver nanoparticles synthesized by flower extract of $R$. dauricum 


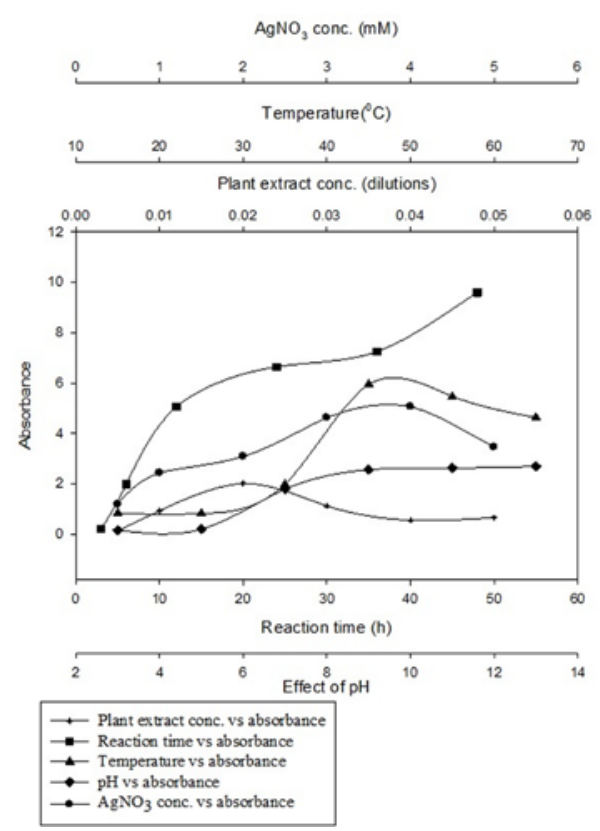

Fig. 4 Effect of various reaction parameters on AgNPs synthesis by water extract of $R$. dauricum flower

consensus with the reports by Ahmad et. al. [19]

\subsection{Optimization of nanoparticle synthesis}

\subsubsection{Concentration of plant extract}

Results of optimization studies are shown in Fig. 4. It is reported [9] in literature that optimum extract to metal salt ratio is required for the synthesis of symmetrical NPs. Diluted flower extract containing $2 \mathrm{~mL}$ extract in $100 \mathrm{~mL}$ water i.e. 0.02 dilution was able to produce the maximum concentration of AgNPs as observed by higher absorbance at $420 \mathrm{~nm}$. Peak observed at 0.02 dilution of plant extract was sharp as compared to other peaks. This indicates the formation of relatively monodispersed particles when 0.02 dilution of plant extract was used.

\subsubsection{Silver ion concentration}

Effect of initial $\mathrm{AgNO}_{3}$ concentration was studied by varying the concentration of $\mathrm{AgNO}_{3}$ from 0.5 $5 \mathrm{mM}$ using 0.02 dilution of plant extract (Fig. 4). Increase in yield of AgNPs was observed when metal salt concentration was increased from 0.5-4 $\mathrm{mM}$. Beyond this there was again fall in absorbance; hence $4 \mathrm{mM}$ concentration of $\mathrm{AgNO}_{3}$ was selected for further experiments. Similar effect of varying concentration of plant extract and silver salt on yield, size and dispersity of silver nanoparticles was reported by Dwivedi et. al. [20].

\subsubsection{Temperature and $\mathrm{pH}$}

Both reaction temperature and $\mathrm{pH}$ play significant role to control the nucleation process of nanoparticle formation. Increase in absorbance of reaction mixture with the increase in incubation temperature evidently depicts the higher synthesis of AgNPs at elevated temperatures [21]. Absorbance increased with increase in the temperature from 25 to $45^{\circ} \mathrm{C}$ and thereafter decreased at higher temperatures (Fig. 4). Moreover, nanoparticles synthesized at higher temperature exhibit surface Plasmon resonance at narrow absorption range indicating monodispersity. Increase in temperature increased the rate of formation of silver nanoparticles from silver ions, retarding the secondary reduction process. Similar results have been reported by Song et.al. [22] and Kaviya et.al. [23].

Effect of reaction $\mathrm{pH}$ on the ability of reductant to synthesise and stabilize metal nanoparticles was reported by Selvakannan et.al. [24]. Effect of $\mathrm{pH}$ on the synthesis of AgNPs by $R$. dauricum was tested over a wider $\mathrm{pH}$ range ( $\mathrm{pH} 3-13)$ (Fig. 4). At acidic $\mathrm{pH}$, larger size NPs were formed, whereas, at alkaline $\mathrm{pH}$, smaller size NP formation was observed. Sathishkumar et.al. [25] reported similar effects of $\mathrm{pH}$ on the size and shape of silver nanoparticles. Nanoparticle aggregation seems to outdo the nucleation process in acidic conditions. At alkaline $\mathrm{pH}$, however, the large numbers of nuclei formation, instead of aggregation, led to the synthesis of more of NPs with smaller diameter. Blue shift in absorption pattern confirmed formation of relatively smaller nanoparticles. This result indicates the very important role played by reaction $\mathrm{pH}$ in controlling the shape and size of the AgNPs synthesis.

\subsubsection{Reaction time}

Absorbance of silver colloidal solution increased with span of time and maximum absorption was observed after $12 \mathrm{~h}$ of reaction (Fig. 4). Reaction time of more than $10 \mathrm{~h}$ is due to less redox potential of silver ions. These findings are in agreement with observations made by Singh et. al. [26]. Aggregation of NPs after $36 \mathrm{~h}$ of reaction was observed, a sign of instability.

\subsection{FTIR spectroscopy analysis}

It has been reported [27] in literature that plant 


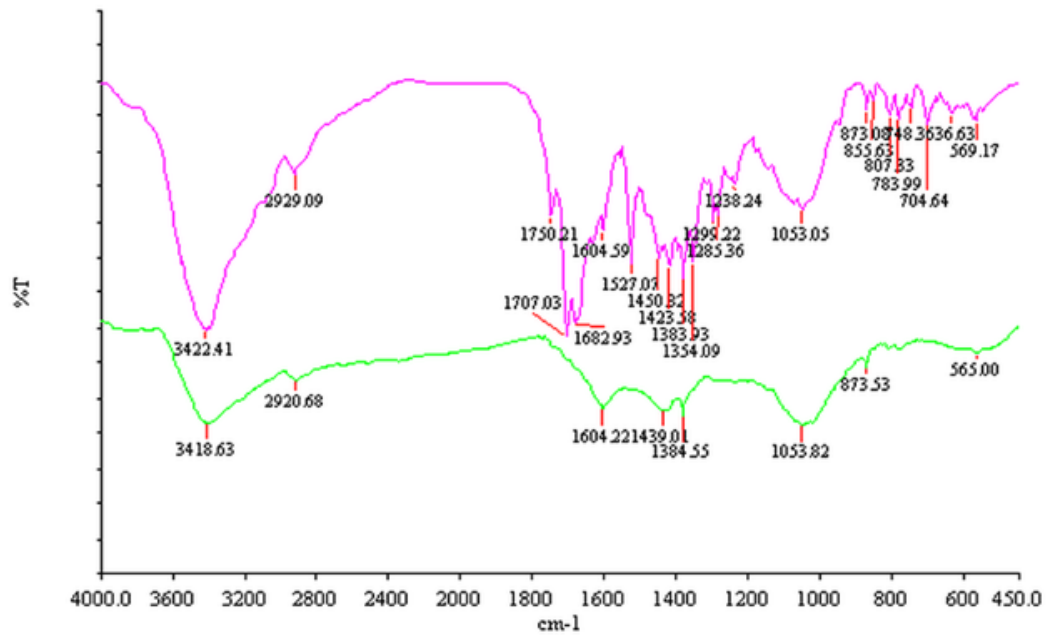

(a)

(b)

Fig. 5 FTIR spectra overlay of (a) flower extract of R. dauricum and (b) synthesized AgNPs capped with flower constituents
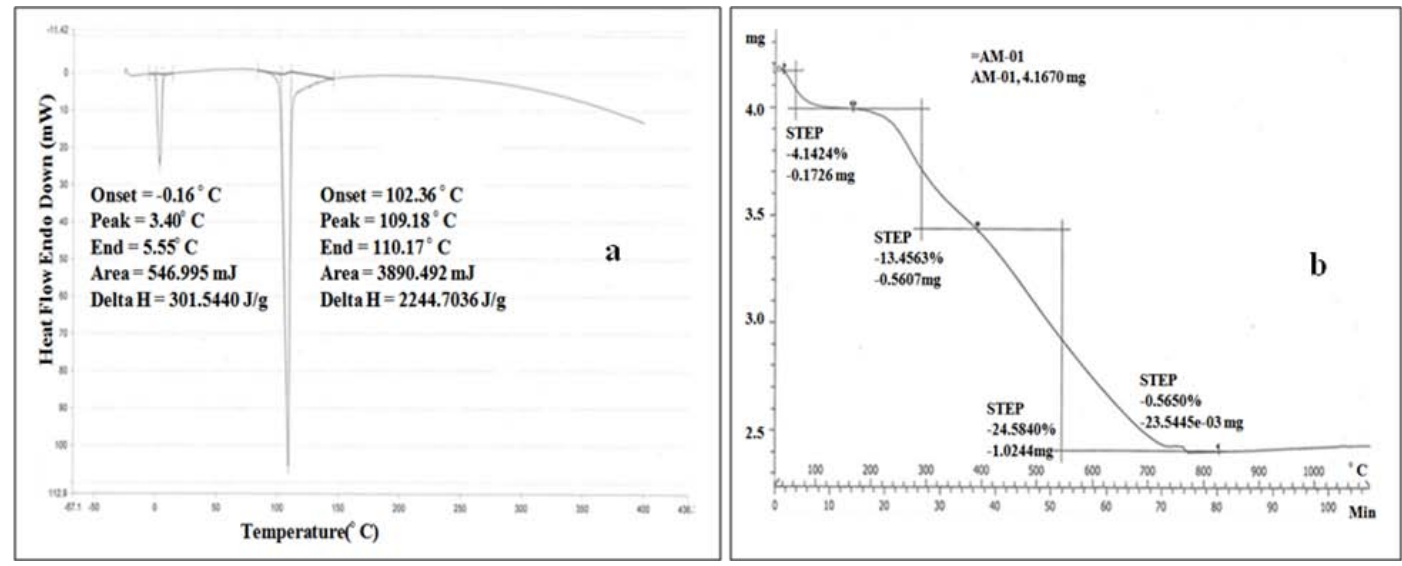

Fig. 6 (a) DSC and (b) TGA analysis of AgNPs synthesized by flower extract of $R$. dauricum
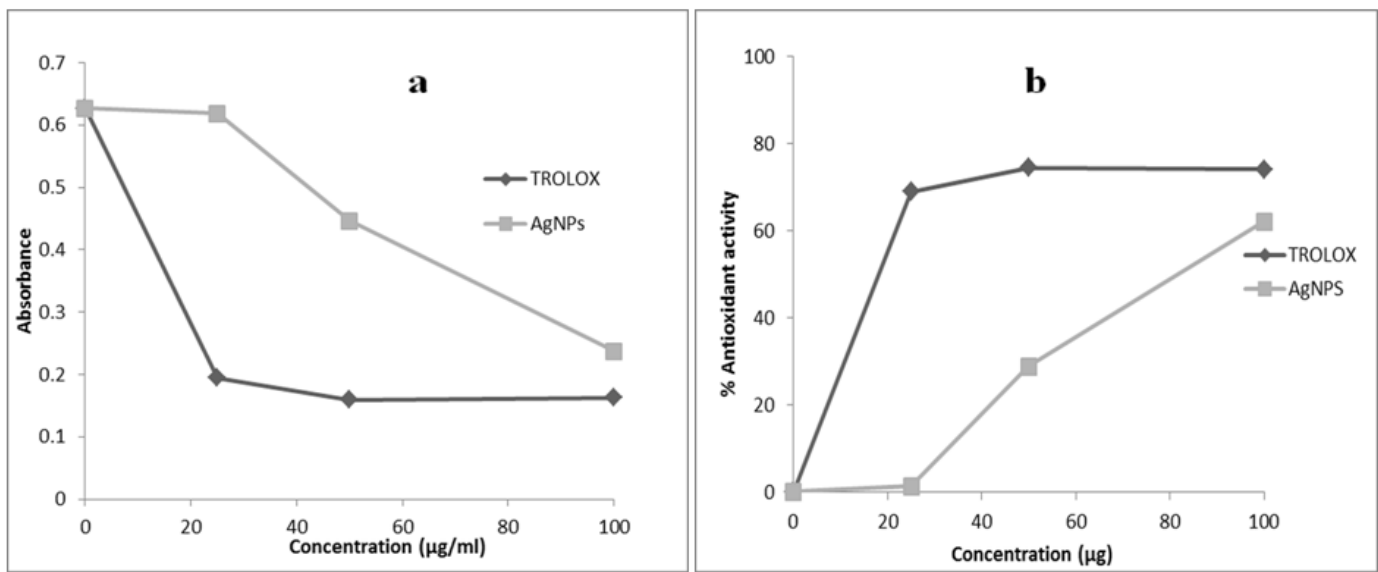

Fig. 7 (a) Scavenging capacity (b) \% anti-oxidant activity of the AgNPs as determined by DPPH assay using TROLOX as a standard

constituents involved in the reduction and capping of nanoparticle can be identified by FTIR technique. FTIR measurements were taken to identify the possible biomolecules responsible for capping and efficient stabilization of the AgNPs synthesized by $R$. dauricum flowers. Fig. 5 shows the FTIR spectra of flower extract of R. dauricum and synthesized AgNPs overlay. The
AgNPs sample shows peaks at 3418, 2920, 1604, 1432 1384, 1053 and $569 \mathrm{~cm}^{-1}$ (Fig. 5) few of which found to be corresponding to peaks in plant extracts spectra. There appear to be no peaks in the amide I and amide II regions characteristic of proteins/enzymes that have been found to be responsible for the reduction of metal ions using microorganisms such as bacteria and fungi for the 
synthesis of AgNPs. The observed peaks are characteristic of flavanones and terpenoids that are very abundant in Rhododendron plant extracts [28,29]. The peaks observed for AgNPs at $3418 \mathrm{~cm}^{-1}$ (-OH structural polymeric association), $2920 \mathrm{~cm}^{-1}$ (chelating compounds), 1384 $\mathrm{cm}^{-1}$ (germinal methyls), $1076 \mathrm{~cm}^{-1}$ (ether linkages) and $569 \mathrm{~cm}^{-1}(\mathrm{C}=\mathrm{C}$ groups or from aromatic rings $)$ suggest the presence of flavanones or terpenoids adsorbed on the surface of MNPs. Such interactions between MNPs and plant constituents have been reported [30] in literature. It seems that the oxidation of aldehydic groups of terpenoids in the molecules to carboxylic acids causes the simultaneous reduction of silver salt followed by capping on the surface of synthesized nanoparticle. These findings are supported by the observations reported by Shankar et. al. [31].

\subsection{DSC and TGA analysis}

DSC study shows the nature of the plant extract compounds loaded on the NPs. Different compounds show their particular characteristic endothermic peaks in DSC. The endothermic peak of AgNPs was found at $100-110{ }^{\circ} \mathrm{C}$ (Fig. 6a) due to transition temperature (Tg). These findings are in agreement with the literature report [32]. The TGA plot of the capped AgNPs prepared using Rhododendron dauricum flower extract (Fig. 6b) showed a steady weight loss in the temperature range of $0-100{ }^{\circ} \mathrm{C}$ due to moisture loss. Between $100-750{ }^{\circ} \mathrm{C}$ weight loss was due to the degradation of organic compounds. Thereafter, above 750 to $1100{ }^{\circ} \mathrm{C}$ there was no degradation and remaining content accounts for silver weight. TGA analysis revealed that starting material was $4.16 \mathrm{mg}$ and total loss of organic matter was $1.81 \mathrm{mg}(35 \%)$.

\subsection{DPPH assay analysis}

Plants contain specific metabolites that are acknowledged to perform a range of purposeful activities. It is well known and also reported in literature that plant mediated nanoparticles synthesis involves sequential reduction followed by capping with these constituents of plants [33]. However, interactions of these components with metals are less well studied and kind of activity they may confer to nanoparticles hasn't been reported so far. We are reporting for the first time antioxidant activity of silver nanoparticles capped with plant constituents possessing free radical scavenging activity. Antioxidant activity of AgNPs is shown in terms scavenging capacity and \% anti-oxidant activity in Fig. $7 \mathrm{a}$ and $7 \mathrm{~b}$, respectively. Capped silver nanoparticles were found to be potent free radical scavenger when compared to standard TROLOX. Free radical scavenging activity of silver nanoparticles at higher concentration $\left(100 \mu \mathrm{g} \mathrm{mL}^{-1}\right)$ is comparable to TROLOX.

An antioxidant works in stopping the oxidation by neutralizing the free radicals produced. In order to neutralize the free radicals, the antioxidant itself undergoes oxidation. The activity and stability of the silver nanoparticles are affected during antioxidation process and also they are oxidized in the presence of air. This antioxidant activity may be due to the capping constituents present in plant extract and present on metal surface.

\section{Conclusion}

Synthesis of nanoparticle is basically a reduction process. This reduction is carried out by chemical or biological reducing agent. In the biological process also the reduction maybe by microbes or its extract or may be by plant extract. Whatever may be the reductant, mode of action is same, only reducing agent differs. In the case of plant extract terpenoids, flavonoids and other phenolic compounds are responsible in the synthesis of nanoparticles, whereas in the case of microbes, short chain peptides or proteins may be involved.

Rhododendron dauricum mediated synthesis of silver nanoparticles approach is a fast, green and economical method which produces highly stable AgNPs. Plant is known to contain flavonoids, phenolic, tri-terpenoids and coumarins compounds that seem to play important role in synthesis, stabilization of AgNPs. The synthesized nanoparticles have antioxidant activity due to capped phenolic compounds and can be used against deleterious effects of free radicals.

\section{Acknowledgements}

The authors AKM and AK gratefully acknowledge the financial support from the CSIR and DBT, respectively, New Delhi, India.

\section{References}

1. Sonvico F, Dubernet C, Colombo P, Couvreur P. Metallic colloid nanotechnology, applications in diagnosis and therapeutics. Curr. Pharm. Design. 2005; 11:2091-2105. http:// dx.doi.org/10.2174/1381612054065738.

2. Shipway AN, Katz E, Willner I. Nanoparticle arrays on surfaces for electronic, optical, and sensor applications. Chem. Phys. Chem. 2000; 1:18-52. DOI: 10.1002/1439-7641(20000804)1:1<18::AIDCPHC18>3.0.CO;2-L.

3. Callegari A, Tonti D, Chergui M. Photochemically grown silver nanoparticles with wavelength-controlled size and shape. Nano Lett. 2003; 3:1565-1568. DOI: 10.1021/n1034757a.

4. Kelly KL, Coronado E, Zhao LL, Schatz GC. The Optical Properties of Metal Nanoparticles: The Influence of Size, Shape, and Dielectric Environment. J. Phys. Chem. B. 2003; 107:668-677. DOI: 10.1021/ jp026731y.

5. Song Y, Kim BS. Rapid biological synthesis of silver nanoparticles using plant leaf extracts. Bioproc. Biosyst. Eng. 2009; 32:79-84. DOI: 10.1007/s00449-008-0224-6.

6. Bar H, Bhui DKr, Sahoo GP, Sarkar P, De SP, Misra A. Green synthesis of silver nanoparticles using latex of Jatropha curcas. Colloids Surf. A. 2009; 339:134-139. DOI: 10.1016/ j.colsurfa.2009.02.008.

7. Xiangqian L, Huizhong X, Zhe-Sheng C, Guofang C. Biosynthesis of Nanoparticles by Microorganisms and Their Applications. $J$. Nanomater. 2011. DOI:10.1155/2011/270974.

8. Kaler A, Nankar R, Bhattacharyya MS, Banerjee UC. Extracellular Biosynthesis of Silver Nanoparticles Using Aqueous Extract of Candida viswanathii. J. Bionanosci. 5; 2011:53-58. DOI:10.1166/ jbns.2011.1040.

9. Iravani S. Green synthesis of metal nanoparticles using plants. Green Chem. 2011; 13:2638-2650. DOI: 10.1039/C1GC15386B. 10. Narayanan KB, Sakthivel N. Green synthesis of biogenic 
metal nanoparticles by terrestrial and aquatic phototrophic and heterotrophic eukaryotes and biocompatible agents. $A d v$ Colloid Interfac. 2010; 156:1-13. DOI: 10.1016/j.cis.2011.08.004.

11. Abilash G, Podila R, Karanam L, Chelli J, Rao AM. Catalytic Reduction of 4-Nitrophenol using Biogenic Gold and Silver Nanoparticles Derived from Breynia rhamnoides. Langmuir. 2011; 27:15268-15274. DOI: 10.1021/1a2034559.

12. Park Y, Hong Y, Weyers A, Kim Y, Linhardt R. Polysaccharides and phytochemicals: a natural reservoir for the green synthesis of gold and silver nanoparticles. Nanobiotechnology IET. 2011; 5:69-78. DOI: 10.1049/iet-nbt.2010.0033.

13. Santhoshkumar T, Rahuman AA, Rajakumar G, Marimuthu S, Bagavan A, Jayaseelan C, Zahir AA, Elango G, Kamaraj C. Synthesis of silver nanoparticles using Nelumbo nucifera leaf extract and its larvicidal activity against malaria and filariasis vectors. Parasitol. Res. 2011; 108:693-702. DOI: 10.1007/s00436-010-21154

14. Thaipong K, Boonprakob U, Crosby K, Cisneros-Zevallos L. Comparison of ABTS, DPPH, FRAP, and ORAC assays for estimating antioxidant activity from guava fruit extracts. $J$. Food Compost. Anal. 2006; 19:669-675. DOI: 10.1016/j.jfca.2006.01.003.

15.Daniel MC, Astruc D. Gold nanoparticles: assembly, supramolecular chemistry, quantum-size-related properties, and applications toward biology, catalysis, and nanotechnology. Chem. Rev. 2004; 104:293-346. DOI: 10.1002/chin.200416213.

16. Mandal S, Rautaray D, Sastry M, Ag+-Keggin ion colloidal particles as novel templates for the growth of silver nanoparticle assemblies. J. Mat. Chem. 2003; 13:3002-3005. DOI: 10.1039/B307000J.

17. Huang J, Li Q, Sun D, Lu Y, Su Y, Yang X, Wang H, Wang Y, Shao $\mathrm{W}, \mathrm{He} \mathrm{N}$, Biosynthesis of silver and gold nanoparticles by novel sundried Cinnamomum camphora leaf. Nanotechnol. 2007; 18: 105104 (11pp). doi:10.1088/0957-4484/18/10/105104. DOI:10. 1088/0957-4484/18/10/105104

18. Morones JR, Elechiguerra JL, Camacho A, Holt K, Kouri JB, Ramírez JT, Yacaman MJ. The bactericidal effect of silver nanoparticles. Nanotechnol. 2005;16:2346. DOI:10.1088/0957-4484/16/10/059.

19. Ahmad N, Sharma S, Alam MK, Singh V, Shamsi S, Mehta B, Fatma A. Rapid synthesis of silver nanoparticles using dried medicinal plant of basil. Colloids Surf. B. 2010; 81:8186. DOI: 10.1016/j.colsurfb.2010.06.029.

20.Dwivedi AD, Gopal K. Biosynthesis of silver and gold nanoparticles using Chenopodium album leaf extract. Colloids Surf. A. 2010; 369:27-33. DOI: 10.1016/j.colsurfa.2010.07.020.

21. Van Hyning DL, Klemperer WG, Zukoski CF. Silver nanoparticle formation: Predictions and verification of the aggregative growth model. Langmuir. 2001; 17:3128-3135. DOI: 10.1021/la000856h.

22.Song JY, Jang HK, Kim BS. Biological synthesis of gold nanoparticles using Magnolia kobus and Diopyros kaki leaf extracts. Process Biochem. 2009; 44:1133-1138.DOI: 10.1016/j.procbio.2009.06.005
23 Kaviya S, Santhanalakshmi J, Viswanathan B, Muthumary J, Srinivasan K. Biosynthesis of silver nanoparticles using Citrus sinensis peel extract and its antibacterial activity. Spectrochim Acta A. 2011; 79:594-598. DOI: 10.1016/j.saa.2011.03.040

24. Selvakannan PR, Swami A, Srisathiyanarayanan D, Shirude PS, Pasricha R, Mandale AB, Sastry M. Synthesis of aqueous Au coreAg shell nanoparticles using tyrosine as a $\mathrm{pH}$-dependent reducing agent and assembling phase-transferred silver nanoparticles at the air-water interface. Langmuir. 2004; 20:7825-7836. DOI: $10.1021 / 1 a 049258$ j.

25. Sathishkumar M, Sneha K, Yun YS. Immobilization of silver nanoparticles synthesized using Curcuma longa tuber powder and extract on cotton cloth for bactericidal activity. Bioresour. Technol. 2010; 101:7958-65. DOI: 10.1016/j.biortech.2010.05.051.

26. Singh C, Sharma V, Naik PK, Khandelwal V, Singh H. A green biogenic approach for synthesis of gold and silver nanoparticles using Zingiber officinale. Dig. J. Nanomater. Biostruct. 2011; 6:535-42.

27. Li S, Shen Y, Xie A, Yu X, Qiu L, Li Z, Zhang Q. Green synthesis of silver nanoparticles using Capsicum annuum L. extract. Green Chem. 2007; 9: 852-858. DOI: 10.1039/B615357G.

28. Cao Y, Chu Q, Ye J. Chromatographic and electrophoretic methods for pharmaceutically active compounds in Rhododendron dauricum. J. Chromatogr. B. 2004; 812:231-240. DOI: 10.1016/j.jchromb.2004.06.048.

29. Cao Y, Lou C, Fang Y, Ye J. Determination of active ingredients of Rhododendron dauricum L. by capillary electrophoresis with electrochemical detection. J. Chromatogr. A. 2002; 943:153-157. DOI: 10.1016/S0021-9673(01)01434-0.

30. Philip] D. Mangifera Indica leaf-assisted biosynthesis of welldispersed silver nanoparticles. Spectrochimica Acta Part A: Mol. Biomol. Spectrosc. 2011; 78:327-331. DO I : 10.1016/j.saa.2010.10.015.

31. Shankar SS, Rai A, Ahmad A, Sastry M. Rapid synthesis of Au, $\mathrm{Ag}$, and bimetallic Au core-Ag shell nanoparticles using Neem(Azadirachta indica)leaf broth.J. Colloid Interface Sci. 2004; 275:496-502. DOI: 10.1016/j.jcis.2004.03.003.

32. Pol VG, Srivastava D, Palchik O, Palchik V, Slifkin M, Weiss A, Gedanken A. Sonochemical deposition of silver nanoparticles on silica spheres. Langmuir. 2002; 18:3352-3357.DOI: 10.1021/la0155552.

33.Khalil MMH, Ismail EH, El-Magdoub F. Biosynthesis of Au nanoparticles using olive leaf extract. Arab.J. Chem. 2010. DOI:10.1016/j.arabjc.2010.11.011.

Copyright:(c) 2012 A.K. Mittal, et al. This is an openaccess article distributed under the terms of the Creative Commons Attribution License, which permits unrestricted use, distribution, and reproduction in any medium, provided the original author and source are credited. 